Current Research in Psychology 1 (2): 75-81, 2010

ISSN 1949-0178

(C) 2010 Science Publications

\title{
Occupational Stress and Family Difficulties of Working Women
}

\author{
${ }^{1}$ Maryam Zarra-Nezhad, ${ }^{1}$ Ali Moazami-Goodarzi, ${ }^{2}$ Leila Hasannejad and ${ }^{2}$ Khadijeh Roushani \\ ${ }^{1}$ Young Researchers Club, Islamic Azad University of Ahvaz, Ahvaz, Iran \\ ${ }^{2}$ Department of Psychology, Faculty of Social Science, \\ Islamic Azad University, Ahvaz Branch, Iran
}

\begin{abstract}
Problem statement: Work and family are the two most important aspects in women's lives. Balancing work and family roles has become a key personal and family issue for many societies. There are many facets in working mother's lives that subject to stresses. They deal with home and family issues as well as job stress on a daily basis. Imbalance between work and family life arises due to a number of factors. Various factors appear to strengthen the brunt of pressure on women. The question was raised whether there is a relationship between occupational stress and family difficulties of working women in Iran. Approach: The purpose of this study was to assess the relationships between occupational stress and family difficulties in working women. A sample of 250 married working women with 2 or more children participated in this study during 2010 in one of the largest city of Iran, Ahvaz. A non-experimental, cross-sectional survey design was conducted using Demographic Information form, The Sources of Work Stress Inventory (SWSI) and Family Adaptability and Cohesion Evaluation Scales-II (FACES-II). Results: Using correlation and regression analysis, results suggested that there were significant positive relationship between levels of occupational stress and family difficulties in working women. Conclusion/Recommendation: Regarding to woman's household tasks and families responsibility, it is important to measure the level of occupational stress in working women and assess relation between occupational stress and family difficulties in order to obtain knowledge for health care providers to provide support to the working women and their families. There is a great need for research on working women, especially concerning the impact and occurrence of job stress on children mental health. Longitudinal data on young childbearing families are needed to examine the complex issues of work-family surrounding the family in today's world.
\end{abstract}

Key words: Occupational stress, Scientific Package of Social Sciences (SPSS), working women, family adaptability and cohesion, longitudinal data, maintenance, demographic, functionalist, Work Stress Inventory (SWSI)

\section{INTRODUCTION}

Balancing work and family roles has become a key personal and family issue for many societies. Work and family are the two most important aspects in people's lives and, contrary to the initial belief that they are distinct parts of life; these domains are closely related (Ford et al., 2007). In all countries the economic development requires an integration of both male and female labor forces. That is men and women both have to contribute to development process of the country as the labor of women contributes to economic growth and poverty reduction.

Traditionally, the major responsibility of women has been perceived to be the maintenance of the family including home and childcare and breadwinning was the main responsibility of men. However, with more and more women entering the workforce and pursuing careers, these clearly defined gender roles were forced to change (Sevim, 2006). Most women do not have responsibility only in one domain anymore; they have to balance the competing demands of both work and family domains (Biçaksiz, 2009).

Family stress theory can be applied to critical work events that negatively affect the family, such as job loss and to chronic work stressors such as role overload, instability, job dissatisfaction, inadequate child care and shift work. 'Families' and 'employment' are inter-related and socially constructed. The functionalist theory of the 'modern' (or 'standard')

(c) 2010 Maryam Zarra-Nezhad, Ali Moazami-Goodarzi, Leila Hasannejad and Khadijeh Roushani. This open access article is distributed under a Creative Commons Attribution (CC-BY) 3.0 license which permits unrestricted use, distribution, and reproduction in any medium, provided the original work is properly credited. DOI: 10.3844/crpsp.2010.75.81 
family was a key element of the 'orthodox consensus' (Giddens and Dallmayr, 1982; Cheal, 1991) that emerged in sociology after the Second World War and persisted until the1970s and even the 1980s. This model viewed the family as an institution that fulfilled universal prerequisites for the survival of human societies. The smooth functioning of societies depended on the proper articulation of the interdependent parts. Therefore change in societies, will go along with change in families in order to meet new needs (Crompton, 2006).

Previous findings (Allen, 2001; Dikkers et al., 2007; Thompson et al., 2004; Grandey et al., 2007; Lapierre et al., 2008) have indicated that employees working in an environment perceived as more familyfriendly reported less work-family conflict (Ahmad and Omar, 2010) .

Stress refers to the generalized, patterned, unconscious mobilization of the body's natural ability (Yahaya et al., 2009). Stress at study is a growing problem for all workers, including women. Furthermore, in women levels of stress-related illness are nearly twice as high as for men (Abdullah et al., 2008).

Occupational stress defined as the harmful physical and emotional responses that occur when the requirement of the job do not match the capabilities, resources or needs of the worker (AL-Hussami, 2008). From that definition, Occupational stress is chronic conditions caused by situation in the workplace that mat negatively affect an individual's job performance and their overall wellbeing (Yahaya et al., 2009).

Many job conditions caused stress among women. These job conditions include little control over work; role ambiguity and conflict; poor relationships with coworkers and supervisors; heavy workload demands; job insecurity and work that are narrow, repetitive and monotonous. Work and family balance issues, also can be stressors for women in the workplace. On the other hand job stress has been linked with depression, musculoskeletal disorders, cardiovascular disease and burnout (Abdullah et al., 2008).

There are many facets in working mother's lives that subject to stresses. They deal with home and family issues as well as job stress on a daily basis. Imbalance between work and family life arises due to a number of factors. Various factors appear to strengthen the brunt of pressure on women. Frequently household duty involves protecting family members: children, the sick and the elderly. Even where men play role in the caring function, usually it is the woman who is the initial career, although she may suffer additional health risks. 'Work-family spillover' is result of the performing multiple roles and this will be accused when the demands from family and home life, interfere with women's ability to perform effectively in the workplace. Having to juggle multiple roles and effect of the pressures from work on one's attitude and behavior within the family also may lead to "work-family spillover' (Younkin, 2010).

Because of difficult situation cased by occupational stress, there are many mothers that would like nothing more than to give up work and spend their time raising their family as best they can. However, financial problems can create a real obstacle here and many mothers find themselves having to go back to work in order to help maintain the family budget. For single mothers in particular, a return to work after having a child is often a necessity. There are a number of problems that working mothers can face: Difficulties with finances, Getting to spend time with the kids, Keeping on top of the housework, Dealing with sickness, Quality time for yourself, Personal illness and stress.

Several researches have indicated that work-family difficulties can make negative influence for individual mentality and physiology. Studies have shown that, compared with their male counterparts, women report higher level of stress in work/family conflicts, gender barriers and career development. Zhang (2010) studied the sources of work stress among women academics in research universities of China. Based on the results of her study, firstly, women academics perceived the demands for career development as highly stressful. The main career challenges for them include the need for renewing knowledge, lack of research productivity and slow career progress. Secondly, gender related barriers increased pressure on women academics. Finally, women academics experienced more difficulties in fulfilling both academic work and family roles. The main conflict situations pertained to "performing both work and family roles very well," "children's education and future" and "lack of time to satisfy personal interests and hobbies."

In another study Ugwu (2010) investigated the multiple role stress sandwich generation female employees experience both at home and at the workplace and how they cope with such stress. 147 sandwich generation women participated in his study. Results showed that sandwich generation women that receive care giving supports either from their husbands or from house-helps experience less stress than their counterparts without such care giving supports and sandwich generation women who cared for the sick aged parents experience more stress than their counterparts who care for healthy aged parents. Sandwich generation female employees who provide 
care giving services to large families did not differ from their counterparts in the normal family size on measures of multiple role stress.

Another study conducted by Fang et al. (2009) examined 121 Chinese professional women on workfamily conflict and their stressors. The result showed that professional women's self-role perceived and social-role perceived have conflicts; education, incoming ratio, professional experience can influence the stress; domesticity satisfaction, family activity, spouse stress, work devotion and work load are stressors of professional women's work-family conflict.

Similarly, Abdullah et al. (2008) assessed occupational stress, social and family difficulties and job contentment of working women in Bangladesh. The study contained the information and situation on working women, the hazards and occupational strains they face at work and in family life in many developed and developing countries including Bangladesh. Besides, this study has also tried to illustrate where the difficulties are and how far these for working women can be solved by giving them emotional sustenance, voicing against the long standing harassment of women and advocating equality for them.

$\mathrm{Lu}$ (2007) also examined the impact of workfamily conflict and the effects of organizational support on working women in Taiwan. 441 women (aged between 15 and 64 years) in paid employment working in three public universities in northern Taiwan formed the sample population for this research. The findings showed that work-family conflict was strongly linked with lower job and family satisfaction, greater stress and more severe physical ailments. Implementing familyfriendly policies and creating a supportive work environment can help working women to manage their work-family conflict and improve their health outcomes.

While much research has been conducted on the occupational stress in men, little research has examined the occupational stress in working mothers and the effect of these stresses on their families. The current study mainly aims at demonstrating job situation for working women and, stresses and difficulties that women experience. It also tries to imply how to resolve occupational stresses by promoting effective management practices, improving interpersonal relations at both profession and home that concern working women.

This study has the potential to provide insight needed by healthcare providers, employers of companies/firms and organizational psychologists to decrease occupational stress of working women and prevent family difficulties caused by those stresses. The main research question is whether there is correlation between occupational stress and family difficulties in working women. To answer this question, the following hypotheses are proposed:

Hypotheses 1: A significant positive relationship will exist between occupational stress and Family difficulties in working women.

Hypotheses 2: A significant multiple relationships will exist between sources of stress and family difficulties in working women.

Hypotheses 3: Work/Home interface (a Sources of Work Stress Scale) is best predictor for Family difficulties in working women.

In the present study the term occupational stress defined as a disorder associated with a job or work. The anxiety may be expressed in the form of extreme tension and anxiety and the development of physical symptoms such as headache or cramps, also called occupational neurosis (Mosby, 2009). This is caused by worry or anxiety at work when a person feels that the demands and pressures of their job are more than they can handle. Stress at work can cause major damage to one's health and overall lifestyle and it is an area that should not be ignored. Family difficulties are miss interaction with family members that involve physical, emotional and psychological problems. Working mothers, as a label, refers to women who are mothers and who work outside the home for income in addition to the work they perform at home in raising their children.

\section{MATERIALS AND METHODS}

The long range goal of this research was to increase the evidence base in the area of working mothers and to provide health care providers information that will enable the development of more effective services to address issues occurring in families of working mothers. The specific purpose of this study was to gain insight regarding the perceptions of working mothers and family difficulties held by occupational stress and the relationships of occupational stress and family difficulties. A nonexperimental, cross-sectional survey design allowed exploration of these topics in a sample of working mothers of more than one child. The research population is the working mothers of one of the largest city of Iran, Ahvaz. Studied sample was obtained through random sampling. 250 married working mothers with 2 or more children participated in this study. The majority of participations were within the age range of 23-49 in 2010. In order to collect the data, each working mother was given the Demographic 
Information form, The Sources of Work Stress Inventory (SWSI) and Family Adaptability and Cohesion Evaluation Scales-II (FACES-II).

Demographic Information form consist of sociodemographic characteristics (age, financial state and educational level) of women and their husbands and information on working period, number of child, children's gender and their ages.

The Sources of Work Stress Inventory (SWSI) (De Bruin and Taylor, 2005) is an instrument, developed in South Africa, to provide a measure of occupational stress that not only indicates a general level of stress, but also draw attention to possible triggers or sources of stress. The information obtained through the questionnaire can be utilized to recognize sources of stress and to address these areas of concern, which could eventually lead to a more health working environment. The SWSI consists of a two parts: the General Work Scale, which forms the first part of the questionnaire as well as Sources of Stress Scale, which forms the second part. The General Work Scale contains Likert-type scale statements aimed to assess the level of stress caused by work, whilst the Sources of Stress Scale, contains statements referring to aspects of work that may cause stress. Respondents are required to answer on a five-point Likert-type scale, where need to indicate how often they experience a certain feeling. The Sources of Stress Scale includes 8 possible sources of stress: Role Ambiguity, Relationships, Tools and Equipment, Job security, Career Advancement, Lack of Autonomy, Work/Home Interface and Workload. SWSI consists of a total of 59 items and takes approximately 20-30 minutes to complete. The Cronbach alpha coefficients for SWSI was 0.92 which seems very high (De Bruin and Taylor, 2005).

Family Adaptability and Cohesion Evaluation Scales-II (FACES-II). Family functioning was measured by the Family Adaptability and Cohesion Evaluation Scales- II (Place, 2005). This 30-item, selfreport instrument was constructed to examine the frequency of occurrence of described situations on a five-point scale ( $1=$ almost never to $5=$ almost always $)$ thus indicating how the informant sees his or her family's adaptability and cohesiveness. The FACES II contains of 16 cohesion items and 14 adaptability items. The scale is designed to measure the insider's view of family dynamics and focuses on all the family members currently living in the home. The internal consistency coefficients were $r=0.88$ for the Cohesion subscale and $r=0.78$ for the Adaptability subscale.

The mothers were asked to complete the surveys. The collected data was imported in to Scientific Package of Social Sciences (SPSS) software. The data were analyzed using multivariate and correlation analyses. Multivariate analyses were used to explore the relationships among the variables. Internal consistency reliability for all scales was tested. Correlation analysis also used to asses' correlation between occupational stress and family difficulties of working women. Using SPSS 18, the items were entered into the alpha formula of the Reliability procedures. The initial Cronbach's alpha in this study for the SWSI was .81 and for the FACES-II was .86, indicating high level of internal consistency.

\section{RESULTS}

Since a random sample was not practical, a sample of working mothers with at least two children under the age of 18 living at home was used. All respondents had at least a high school education with $59 \%$ having college degrees. The average number of children per family in this study was 2, with the range being from 2-5 children. $45 \%$ of them were boy and $55 \%$ were girl and the average of age was 8.2 years. The annual income for $61 \%$ of working women was below the average. When respondents were asked to indicate their perception of the adequacy of their income, $58 \%$ said they could only meet necessities and $22 \%$ said their income allowed them to afford more than just necessities. The remaining $20 \%$ reported that their incomes were not at all adequate. The respondents reported the working period ranged from 1-10 years. The mean working period was 3.2 years. The average age of the respondents was 32 years.

Prior to testing the study's hypotheses, descriptive statistics were computed (mean and standard deviation and Cronbach's alpha) to assure that inferential assumptions were met. These are shown in Table 1.

The first main question is whether there is a significant positive relationship between occupational stress and family difficulties in working women. Simple correlations between General Work Scale, Sources of Stress Scale and FACES-II used to answer this question (Table 2). Results indicated a significant $(\mathrm{p}<0.01)$ positive correlations between General Work Scale,

Table 1: The current study's means, standard deviation and reliability statics for the SWSI and FACES-II

\begin{tabular}{lrll}
\hline Measure & Means & SD & Cronbach's Alpha \\
\hline Role ambiguity & 13.71 & 5.04 & 0.78 \\
Relationships & 16.02 & 8.01 & 0.90 \\
Tools and equipment & 11.18 & 5.01 & 0.92 \\
Career advancement & 12.01 & 5.41 & 0.81 \\
Job security & 9.00 & 4.03 & 0.84 \\
Lack of authority & 14.87 & 5.12 & 0.85 \\
Work/Home interface & 16.45 & 7.10 & 0.74 \\
Workload & 16.11 & 6.04 & 0.79 \\
General work stress & 15.13 & 6.00 & 0.83 \\
Cohesion & 6.25 & 7.78 & 0.81 \\
Adaptability & 7.91 & 7.66 & 0.80 \\
\hline p<0.01 & & &
\end{tabular}


Table 2: Correlations between general work scale, sources of stress scale and FACES-II

\begin{tabular}{llll}
\hline Measure & GWS & Cohesion & Adaptability \\
\hline Role ambiguity & 0.41 & 0.34 & 0.38 \\
Relationships & 0.32 & 0.54 & 0.48 \\
Tools and equipment & 0.43 & 0.31 & 0.39 \\
Career advancement & 0.30 & 0.34 & 0.41 \\
Job security & 0.45 & 0.35 & 0.40 \\
Lack of authority & 0.42 & 0.45 & 0.39 \\
Work/Home interface & 0.58 & 0.61 & 0.74 \\
Workload & 0.54 & 0.51 & 0.67 \\
Cohesion & 0.56 & - & 0.61 \\
Adaptability & 0.59 & 0.61 & - \\
\hline
\end{tabular}

$\mathrm{p}<0.01$

Table 3: Regression between FACES-II and sources of stress scale

\begin{tabular}{lll}
\hline Model & Multiple R & F \\
\hline Sources of Stress & 0.59 & 6.102
\end{tabular}

$\mathrm{p}<0.01$

Table 4: Coefficients obtained from the regression between FACES-II and sources of stress scale

\begin{tabular}{llll}
\hline Model & Beta & $\mathrm{t}$ & Sig. \\
\hline Work/home interface & 0.470 & 1.62 & 0.000 \\
Workload & 0.581 & 2.64 & 0.002 \\
\hline $\mathrm{p}<0.01$ & & &
\end{tabular}

Sources of stress scale and FACES-II. The correlations magnitude ranged between 0.30-0.59. These results supported the first hypothesis, that is, there is a significant positive relationship exists between occupational stress and Family difficulties in working women.

A series of regression analysis were conducted to gain information on the amount of variance in family difficulties explained by various sources of stress that is measures by SWSI. The R square value is reported for the regression results. Table 3 presents the model summery and as shown there is a high multiple relationship between the various sources of stress and family difficulties ( $M R=0.59 ; \mathrm{p}=0.000)$. This result supported the second hypothesis, that is, a significant multiple relationships will exist between Sources of Stress and Family difficulties in working women.

The standardized coefficients are presented in Table 4. Results revealed that Work/Home interface $(\beta$ $=0.470 ; \mathrm{p}=0.000)$ and Workload $(\beta=0.581 ; \mathrm{p}=$ 0.000 ) are best predictors of family difficulties. This finding supported the third hypothesis, that is, work/home interface is best predictor for family difficulties in working women.

\section{DISCUSSION}

This study examined relationship occupational stress and family difficulties of working women in Iran. From the results noted, occupational stress (as measured by the General Work Scale and Sources of
Stress Scale) was strongly related to family difficulties of working women. The relationship proved to be strongly significant suggesting that mothers who experience high levels of stress, would also experience difficulty in family adaptability and cohesion. The study analyzes that despite there is increasing number of career and professional women, women are still very much troubled and apprehensive about their present a lot and crave fundamental changes in their family adaptability and cohesion, occupational stress and economic status.

In this study multiple regression analysis were conducted to reveal the multiple relationship between vasigus sources of stress (as measured the SWSI (De Brovo and Taylor, 2005)) and family difficulties and to determine which of the source of stress, best predicts the development of family difficulties. The results indicated that there is strong multiple relationship between various sources of stress and family difficulties (MR $=0.59 ; \mathrm{p}=$ 0.000 ). Furthermore it was found that Work/Home interface and Workload best predicted family difficulties. These findings are in line with many findings such as Younkin (2010); Zhang (2010); Ugwu (2010); Fang et al. (2009); Abdullah et al. (2008) and Lu (2007).

\section{CONCLUSION}

Balancing work and family roles has become a key personal and family issue for women. Employers and family studies specialists find that the changing family structure is a major source of stress and role strain in both the work place and the home. Women need to feel that their work is important and essential and that they are not sacrificing their child's well being in order to benefit themselves. The danger involved is that the mothers could feel so guilty in working that they feel that they are abandoning their child to the caregivers that they are in contact with daily. There is another dilemma for working women; they always feel that home is their original domain, which they have to sustain in all circumstances. Women usually have a feeling of guilt for sparing less time for their maternal responsibilities and family. This dual responsibility proves the double burden on her and that makes her to fight concurrently on two fronts.

Sources of work stress, including role ambiguity, relationships, tools and equipment, lack of autonomy, career advancement, job security, workload and work/home interface have been implicated in affecting family functioning.

Though men are increasingly contributing to family responsibilities, women still provide more than their fair share of care giving responsibilities at home. 
Sixty-six percent of all informal caregivers are female and $37 \%$ of them care for children and grandchildren under the age of 18. These women will also spend 4.6 years caring for elderly family members. Capture between care for the young and elderly, working women aged 30 to their 60s are known today as the "sandwich generation." Issues like job security, health benefits, work scheduling and other commonly recognized core union topics actually relate to work and family issues. Therefore an effort should be made to reframe work and family issues as core labor issues. We recommend that unions and funders advance the dialogue around work and family issues and young workers; unions begin to include work and family and young workers' issues in their campaign plans; unions experiment with the use of social media through pilot projects that are planned, implemented and evaluated; and that young workers in unions be engaged, supported, mentored and given opportunities to lead (Firestein et al., 2010).

Findings of this study can produce important information allowing development of educational tools and interventions and can raise awareness of workfamily issues; by witch occupational stress around the working women can be decreased. These findings can be useful for organizations, companies and health professionals to help working women reduce problems related to work-family issues. There is a great need for research on working women, especially concerning the impact and occurrence of job stress on children mental health. Longitudinal data on young childbearing families are needed to examine the complex issues of work-family surrounding the family in today's world.

\section{REFERENCES}

Abdullah, R., S. Jahan and S. Saha, 2008. Occupational stress, social and family difficulties and job contentment of working women: Bangladesh perspective. J. Bus. Econ., 3: 139-153. http://www.daffodilvarsity.edu.bd/library/opac/Abstructv iewlist.php?showmaster=opacview $\&$ articleid $=6945$

Biçaksiz, P., 2009. The effects of gender role ideology, role salience, role demands and core selfevaluations on work-family interface. Msc. Thesis. Middle East Technical University. http://etd.lib.metu.edu.tr/upload/12610950/index.pdf

Cheal, D.J., 1991. Family and the state of theory. 1st Edn., Harvester Wheatsheaf, Virginia, ISBN: 0745005144, pp: 213.

Crompton, R., 2006. Employment and the Family: The Reconfiguration of Work and Family Life in Contemporary Societies. 1st Edn., Cambridge University Press, New York, ISBN: 9780521840910, pp: 252.
Ahmad, A. and Z. Omar, 2010. perceived workplace culture as an antecedent of job stress: The mediating role of work-family conflict. J. Soc. Sci., 6: 369-375. DOI: 10.3844/jssp.2010.369.375

Yahaya, A., N. Yahaya, K. Arshad, J. Ismail and S. Jaalam et al., 2009. Occupational stress and its effects towards the organization management. J. Soc. Sci., 5: 390-397. DOI: 10.3844/jssp.2009.390.397

AL-Hussami, R.N.M., 2008. A study of nurses' job satisfaction: The relationship organizational commitment, perceived organizational support, transactional leadership, transformational leadership and level of education. Eur. J. Sci. Res., 22: 286-295.

http://www.eurojournals.com/ejsr_22_2_14.pdf

De Bruin, G.P. and N. Taylor, 2005. Development of the sources of work stress inventory. South African J. Psychol., 35: 748-765. http://ujdigispace.uj.ac.za:8080/dspace/handle/102 $10 / 2869$

Fang, W., Y. Feng and L. Wu, 2009. The stressors in professional women's work-family conflict: A Chinese study. J. Canadian Soc. Sci., 5: 62-67. http://cscanada.net/index.php/css/article/viewFile/3 $62 /$ pdf_200

Firestein, N., D. King and K. Quan, 2010. New approaches to organizing women and young workers," Labor Project for Working Families, Cornell ILR Labor Programs and UC Berkeley Labor Center. http://www.workingfamilies.org/learnmore/pdf/NewApproachestoOrga nizingWomenand YoungWorkers.pdf

Ford, M.T., B.A. Heinen and K.L. Langkamer, 2007. Work and family satisfaction and conflict: a metaanalysis of cross-domain relations. J. Applied Psychol., 92: 57-80. DOI: 10.1037/00219010.92.1.57

Giddens, A. and F.R. Dallmayr, 1982. Hermeneutics and Social Theory' in Profiles and Critiques in Social Theory. In: Readings on the family and society, Goode, W.J. (Ed.). University of California Press, USA., ISBN: 0520049330, pp: 1-17.

Lu, Y., 2007. The impact of work-family conflict on working women in Taiwan: the effects of organizational support," Phd. Thesis. Queensland University of Technology, Brisbane, Australia. http://eprints.qut.edu.au/16536/

Mosby, I., 2009. Mosby's Medical Dictionary. 8th Edn., Mosby/Elsevier, New York, USA., pp: 1998.

Place, M., 2005. The Family Adaptability and Cohesion Evaluation Scale (FACES): An instrument worthy of rehabilitation? J. Psychiatrist, 29: 215-218. DOI: 10.1192/pb.29.6.215 
Sevim, S.A., 2006. Religious tendency and gender roles: Predictors of the attitudes toward women's work roles. Soc. Behav. Personal. Int. J., 34: 77-86. DOI: $10.2224 /$ sbp.2006.34.1.77

Ugwu, L., 2010. Employed "sandwich" generation women: coping with work/ family conflicts. European J. Soc. Sci., 15: 396-410. http://www.eurojournals.com/ejss_15_3_10.pdf
Younkin, F.L., 2010. Work-family spillover, division of labor and relationship satisfaction. MSc. Thesis. Ohio State University. http://etd.ohiolink.edu/sendpdf.cgi/Lotspeich\%20Younkin\%20Felisha.pdf?osu 1275417957

Zhang, L., 2010. A study on the measurement of jobrelated stress among women academics in research universities of China. Frontiers Educa. China, 5: 158-176. DOI: 10.1007/s11516-010-0011-4 